УДК 338

\title{
ИННОВАЦИОННЫЙ БИЗНЕС РФ: ИТОГИ ПЕРВОГО ГОДА ПАНДЕМИИ
}

\section{Степанова Елена Викторовна} к.э.Н., доцент ФГАОУ ВО «Мурманский государственный технический университет»

Аннотация: в статье проведен анализ некоторых итогов развития инновационного бизнеса России в период пандемии. Выявляются проблемы деятельности IT-компаний в период эпидемиологических ограничений и пути их решения. Сделан вывод о том, что высокотехнологичные компании в условиях кризиса испытывают примерно те же трудности, что и остальные компании.

Ключевые слова: высокотехнологичный бизнес, уровень инновационной активности, меры поддержки IT-индустрии.

\section{INNOVATIVE BUSINESS OF THE RUSSIAN FEDERATION: RESULTS OF THE FIRST YEAR OF THE PANDEMIC}

\section{Stepanova Elena Viktorovna}

\begin{abstract}
: the article analyzes some of the results of the development of innovative business in Russia during the pandemic. The problems of IT companies' activities during the period of epidemiological restrictions and ways to solve them are revealed. It is concluded that high-tech companies are experiencing approximately the same difficulties as other companies in a crisis.

Key words: high-tech business, the level of innovation activity, measures to support the IT industry.

Ограничения по эпидемиологическим требованиям со стороны внутреннего и внешнего окружения оказали на экономическое развитие РФ
\end{abstract}




\section{НАУКА, ОБЩЕСТВО, ЛИЧНОСТЬ: ПРОБЛЕМЫ И ПЕРСПЕКТИВЫ ВЗАИМОДЕЙСТВИЯ В СОВРЕМЕННОМ МИРЕ}

существенное влияние. Не стал исключением и высокотехнологичный бизнес один из локомотивов инноваций.

За прошедший 2020 год в глобальном инновационном индексе Россия занимает 47 место [1, с. 32] из 131 страны, что на один пункт ниже значения 2019 года. По достигнутым результатам показатель нашей страны - 58 место [1, с. 34,36], по показателю ресурсов - 42-е [1, с. 34,36]. Некоторые значимые показатели глобального инновационного индекса представлены в таблице 1 [1, c. 315].

Таблица 1

Показатели России в рейтинге глобального инновационного индекса

\begin{tabular}{|c|c|}
\hline Показатели & Место в рейтинге \\
\hline Энергоэффективность & 115 \\
\hline Верховенство права & 114 \\
\hline Сертификация ИСО 14001 & 106 \\
\hline Инвестиции & 106 \\
\hline Качество регулирования & 105 \\
\hline
\end{tabular}

Уровень инновационной активности в стране снижался в период пандемии и в настоящее время пока еще не появляются тенденции к улучшению: только каждая десятая компания планирует реализацию новшеств в 2020-2025 гг. [2]

Наиболее невнятными позициями инновационной среды выступили: степень развитости рынков, состояние институтов и инфраструктуры.

Вместе с тем, не все так неутешительно: к примеру, несколько отечественных компаний - 1C, Mail.ru, Playrix, Тинькофф-Банк, Wildberries и «Яндекс» - входят в топ-100 претендентов на мировое лидерство в технологическом секторе, по версии консалтингового агентства BCG [3].

В 2016-2019 годах среднегодовая выручка российских компаний составляла 1,8 млрд долларов, в то время как в среднем по списку топ-100 она равнялась 2 млрд. Но Иван Котов, управляющий директор и партнер BCG, отметил, что, «хотя средний показатель выручки российских претендентов пока немного ниже, чем в среднем по списку топ-100, по темпам роста они превосходят технологических игроков из индекса S\&P 500 в фантастические шесть раз. Они успешно работают не только на внутреннем рынке, но и за его пределами. Их секрет - инновации, новые, неожиданные для конкурентов и 
традиционных компаний подходы, способные изменить не только свою, но и другие отрасли, цепочки поставок и рынки» [3].

Пандемия оказала существенное влияние и на деятельность отечественных IT - фирм, несмотря на то, что они обладают ресурсами, которые в большинстве своем, не зависят от внешних факторов.

По итогам опроса технологических компаний [4] были сформулированы основные проблемы IT-компаний в период пандемии, которые приведены в таблице 2.

Таблица 2

Основные проблемы деятельности IT-компаний в период пандемии

\begin{tabular}{|c|c|c|}
\hline & Проблемы & $\begin{array}{c}\% \\
\text { опрошенных }\end{array}$ \\
\hline 1 & 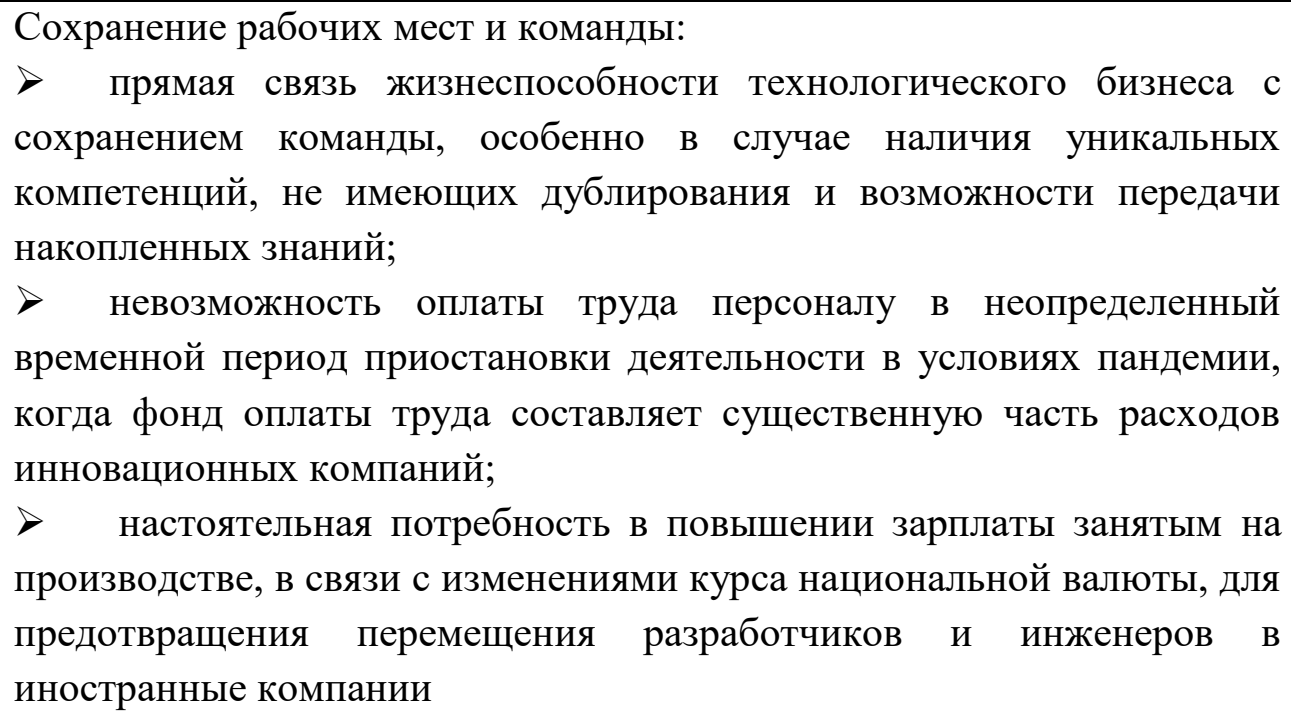 & $51 \%$ \\
\hline 2 & $\begin{array}{l}\text { Недостаток ликвидности } \\
>\quad \text { недостаток ликвидности наряду с сохранением обязательных } \\
\text { платежей по налогам, кредитам, аренде, оплате труда, платежам } \\
\text { контрагентам как внутри страны, так и за рубежом приводит к } \\
\text { стремительному ухудшению финансового состояния компаний; } \\
>\quad \text { сокращение ликвидности вызывается нарушением договоров по } \\
\text { срокам оплаты контрактов, в том числе по контрактам с } \\
\text { организациями с государственным капиталом. Это, в свою очередь, } \\
\text { приводит к увеличению дебиторской задолженности }\end{array}$ & $36 \%$ \\
\hline 3 & $\begin{array}{l}\text { Уплата налогов } \\
>\quad \text { сдвиг платежей по налогам на несколько месяцев не может быть } \\
\text { решением проблемы, так как налоговые выплаты никто не отменял }\end{array}$ & $52 \%$ \\
\hline 4 & Перечисление взносов в страховые фонды & $35 \%$ \\
\hline 5 & Погашение банковских кредитов & $28 \%$ \\
\hline
\end{tabular}




\section{НАУКА, ОБЩЕСТВО, ЛИЧНОСТЬ: ПРОБЛЕМЫ И ПЕРСПЕКТИВЫ ВЗАИМОДЕЙСТВИЯ В СОВРЕМЕННОМ МИРЕ}

\section{Продолжение таблицы 2}

\begin{tabular}{|c|c|c|}
\hline 6 & $\begin{array}{l}\text { Затрудненный доступ к займам на развитие, не имея активов для } \\
\text { привлекательной залоговой базы }\end{array}$ & $28 \%$ \\
\hline 7 & $\begin{array}{l}\text { Оплата аренды и других обязательных платежей } \\
\text { > налоговая инспекция предъявляет к оплате документы по } \\
\text { обязательным платежам и блокирует счета исходя из непредставления } \\
\text { различных форм отчетности }\end{array}$ & $39 \%$ \\
\hline 8 & $\begin{array}{l}\text { Tрудности сбыта } \\
\text { с снижение количества сделок с зарубежными компаниями и } \\
\text { проблемы с выплатами по действующим договорам }\end{array}$ & $46 \%$ \\
\hline 9 & $\begin{array}{l}\text { Сложности взаимодействия с зарубежными контрагентами } \\
>\quad \text { изменение курса рубля, что вызывает рост цен на импортные } \\
\text { комплектующие и появление курсовой разницы по уже действующим } \\
\text { контрактам (при импорте комплектующих необходимо оплатить НДС, } \\
\text { что приводит к кассовым разрывам) }\end{array}$ & $32 \%$ \\
\hline 10 & $\begin{array}{l}\text { Трудности при закупке необходимых составляющих производства } \\
\text { п проблемы во взаимоотношениях с зарубежными партнерами, } \\
\text { вызванные отменой авиасообщений, в том числе невозможность } \\
\text { отправки продукта по существующим контрактам и обмена } \\
\text { подлинниками документов, что создает угрозу срыва экспортных } \\
\text { поставок }\end{array}$ & $30 \%$ \\
\hline 11 & $\begin{array}{l}\text { Критично высокая степень неопределенности } \\
\text { стохастические изменения, трудность прогнозирования и } \\
\text { отсутствие достоверной информации для принятия долгосрочных } \\
\text { планов }\end{array}$ & $30 \%$ \\
\hline
\end{tabular}

Наиболее актуальными мерами поддержки, по мнению представителей высокотехнологичного бизнеса, могли бы стать:

$>$ частичное субсидирование зарплаты сотрудников на время приостановки деятельности;

$>$ применение льготной налоговой ставки, отсрочка налоговых платежей;

$>$ сокращение страховых выплат;

$>$ введение программ льготного кредитования;

$>$ частичное субсидирование арендной платы и оплаты коммунальных платежей;

упрощение процедур торговли, в частности, импорта для приобретения необходимых комплектующих. 
В апреле 2020 года в правительстве стали обсуждаться меры поддержки высокотехнологичных компаний в сфере малого и среднего бизнеса. В июле 2020 года был принят Федеральный закон от 31.07.2020 N 265-Ф3 «О внесении изменений в часть вторую Налогового кодекса Российской Федерации», согласно которому, в целях развития IT-индустрии для российских организаций, осуществляющих деятельность в области информационных технологий, разрабатывающих и реализующих разработанные ими программы для ЭВМ, соответствующих установленным условиям, предусматривается:

$>$ снижение с 2021 года действующего тарифа страховых взносов с 14\% до 7,6\% (на обязательное пенсионное страхование ОПС - 6,0\%, на обязательное соцстрахование ОСС по временной нетрудоспособности и материнству ВНиМ 1,5\%, на обязательное медицинское страхование ОМС - 0,1\%);

$>$ снижение ставки налога на прибыль с $20 \%$ до $3 \%$ (в федеральный бюджет 3\%, в бюджет субъекта РФ - 0\%) [5].

Аналогичные условия налогообложения установлены также для организаций, осуществляющих деятельность по проектированию и разработке изделий электронной компонентной базы и электронной (радиоэлектронной) продукции [5].

Пересмотрен порядок освобождения от НДС операций по реализации исключительных прав на программы, включенные в Единый реестр программ для электронных вычислительных машин и баз данных.

С 01 января 2021 года все операции по продаже программного обеспечения ПО при заключаемых лицензионных договорах облагается НДС в размере $20 \%$. По сути, это означает, что все импортное ПО с января текущего года подорожало на $20 \%$. То есть, с одной стороны, льготы увеличились, а с другой - сократилось число компаний, имеющих право претендовать на эти льготы.

В свете того, что в условиях пандемии многие компании приостановили проекты по внедрению инноваций и нового программного обеспечения, подорожание импортного ПО не лучшим образом скажется на функционировании IT-бизнеса.

Таким образом, можно сделать вывод о том, что, несмотря на значительные преимущества высокотехнологичных компаний на российском рынке, их кажущуюся устойчивость к кризисам, они испытывают на 
сегодняшний день примерно те же трудности, что и остальные участники рынка.

\section{Список литературы}

1. Global Innovation Index 2020.Who Will Finance innovation? 13th ed.//Dutta S., Lanvin B., Wunsch-Vincent S. (eds.) Cornell Uneversity, INCEAD, WIPO, 2020. URL:http://www.wipo.int/edocs/en/ wipo_pub_gii_2020.pdf.

2. Наука. Технологии. Инновации. URL: http://issek. hse.ru/news/4221723 87. html.

3. Технологическое лидерство: шесть российских компаний - в списке // Эксперт. №8. 23.11.2020. https://expert.ru/expert/2020/48/tekhnologiches koe-liderstvo-shest-rossijskikh-kompanij-v-spiske/.

4. Итоги опроса технологических компаний «Меры поддержки технологического бизнеса»// АО РВК.06.04.2020. https://services.rvc.ru/upload/ iblock/2c8/2c8c37b900d9814d53bc79f591512a9a. pdf.

5. Федеральный закон от 31.07.2020 N 265-Ф3 «О внесении изменений в часть вторую Налогового кодекса Российской Федерации» http:// www.consultant.ru/document/cons_doc_LAW_358732/.

(C) Е.В. Степанова, 2021 